\title{
Parasitic-Element-Loaded UWB Antenna with Band-Stop Function for Mobile Handset Wireless USB
}

\author{
Yohan Lim, ${ }^{1}$ Young Joong Yoon, ${ }^{1}$ and Byungwoon Jung ${ }^{2}$ \\ ${ }^{1}$ Department of Electric and Electronic Engineering, Yonsei University, Seoul 120-749, Republic of Korea \\ ${ }^{2}$ MC R\&D Campus B, 60-39, LG Electronics, Seoul 153-801, Republic of Korea
}

Correspondence should be addressed to Young Joong Yoon, yjyoon@yonsei.ac.kr

Received 7 August 2012; Revised 5 October 2012; Accepted 6 October 2012

Academic Editor: Renato Cicchetti

Copyright () 2012 Yohan Lim et al. This is an open access article distributed under the Creative Commons Attribution License, which permits unrestricted use, distribution, and reproduction in any medium, provided the original work is properly cited.

\begin{abstract}
A UWB antenna loaded by parasitic elements for wireless USB of mobile handsets is proposed for UWB service in which a bandstop function of $5.725-5.825 \mathrm{GHz}$ WLAN band is required. Two kinds of parasitic elements are incorporated into a rectangular radiator to obtain enhanced impedance bandwidth and band-stop function. The proposed antenna is very compact in size. Wide bandwidths of $3.15-4.75 \mathrm{GHz}$ and $7.2-10.2 \mathrm{GHz}$ are achieved while $5.725-5.825 \mathrm{GHz}$ is notched. Three different shapes of conventional mobile terminals are also considered for measurement.
\end{abstract}

\section{Introduction}

Ultra-wideband (UWB) antenna technology has been one of the most fascinating design areas in indoor communications, and it has been used with a variety of antennas [1-10]. It has the merits of high-speed transmission rate, low power consumption, and simple hardware configuration over conventional wireless communication systems. The main challenge for UWB antennas is to maintain high performance over a large bandwidth while having small dimensions. Another design concern is that a UWB antenna can allow a potential interference with a wireless local area network (WLAN) [11-13]. Recently, there have been attempts to include UWB systems in USB dongles [1417]. However, previous UWB antennas for wireless USB devices are too large to be inserted into the terminals of mobile handsets, and interference with the WLAN was not considered in these designs.

In this paper, a UWB antenna for wireless USB for mobile handsets is proposed that has both small size and a band-stop function at the upper WLAN band of $5.725-5.825 \mathrm{GHz}$. Two parasitic elements are used to achieve wideband characteristics and the band-stop function. A tapered and folded feed line is also used to obtain an enhanced impedance matching characteristic [18]. All simulations in this work were carried out using CST Microwave Studio. A design example of the proposed antenna is demonstrated.

\section{Antenna Structure}

The three dimensional configuration of the proposed antenna with its planar figure is shown in Figure 1. A rectangular radiator and parasitic elements are fabricated on the FR4 substrate with a dielectric constant of 4.5 and a height of $1 \mathrm{~mm}$ and mounted in the top left-hand corner of a mobile handset board. The optimum design parameters are: $\mathrm{AW}=6.4 \mathrm{~mm}, \mathrm{AL}=6 \mathrm{~mm}, \mathrm{SL}=4.95 \mathrm{~mm}$, $\mathrm{GW}=8 \mathrm{~mm}, \mathrm{GL}=2.5 \mathrm{~mm}, \mathrm{BW}=2.6 \mathrm{~mm}, \mathrm{FL}=7 \mathrm{~mm}$, and $\mathrm{FW}=1.5 \mathrm{~mm}$. The size of the radiator is $6.4 \mathrm{~mm} \times$ $6 \mathrm{~mm} \times 3 \mathrm{~mm}$, and the antenna clearance is $14.4 \mathrm{~mm} \times$ $16 \mathrm{~mm}$. It has not only very compact size, but also low profile. The PCB size is $35 \mathrm{~mm} \times 80 \mathrm{~mm} \times 1 \mathrm{~mm}$, which is typical for mobile handsets. The proposed antenna is composed of a rectangular radiator, a folded and tapered feed line, a parasitic element (1) on each side of the folded feed line, and a parasitic element (2) on each side of the rectangular radiator. The rectangular radiator has similar characteristics to general planar monopoles [4]. The parasitic elements (1) and (2) are connected to each other, and each 


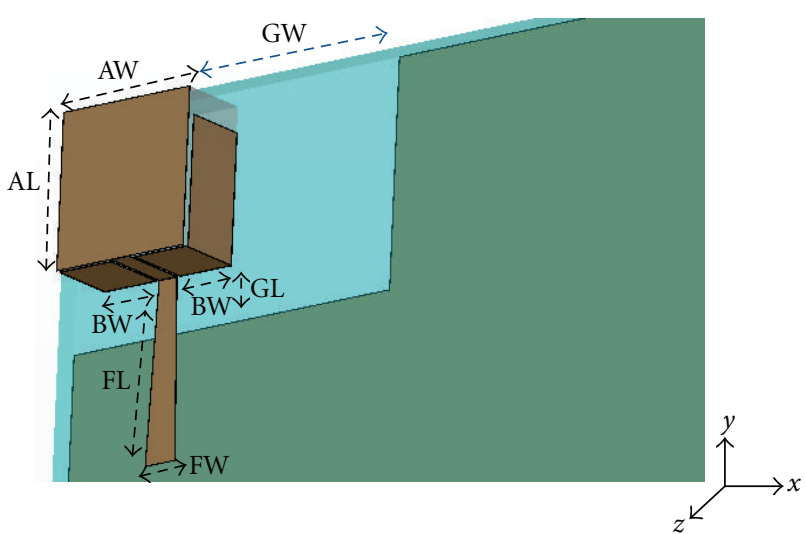

(a)

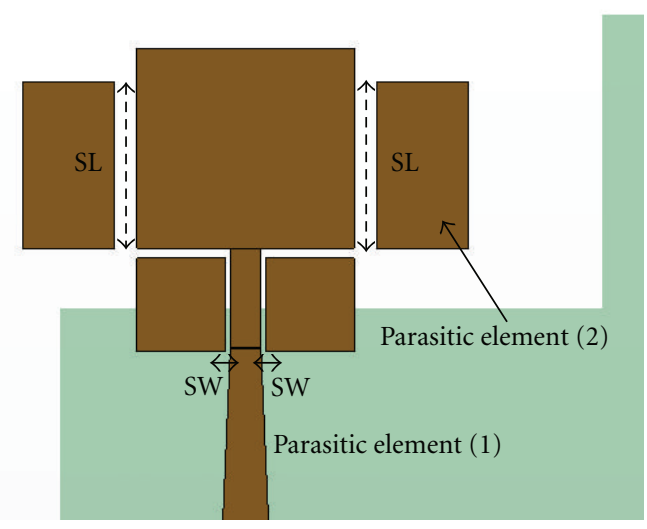

(b)

Figure 1: Configuration of the proposed antenna. (a) Designed structure, (b) planar figure.

element has a different role. The parasitic elements (1) can operate as additional radiators due to their coupling with the rectangular radiator, and these elements radiate at the higher end of the band. The gaps between the radiator and the parasitic elements (2) operate as lambda/4 short stubs, achieving a band-stop function at $5.725-5.825 \mathrm{GHz}$ in the upper WLAN band by incorporating a parasitic element (2) into each side of the radiator [2, 3]. These also act as resonators that confine the energy formed by the fields around the $5.725-5.825 \mathrm{GHz}$ bands, and the stop band can be made to correspond to the length (SL) of the parasitic element (2). A folded and tapered feed line is used for miniaturization of the proposed antenna and for enhanced impedance matching.

\section{Simulated Results Analysis}

Based on our simulations using CST Microwave Studio, the proposed antenna is designed and optimized to operate in all UWB bands of 3.15-4.75 GHz and 7.2-10.2 GHz for VSWR less than 2, including the band-stop function of 5.725$5.825 \mathrm{GHz}$ in the upper WLAN. According to the return loss characteristics of the proposed antenna, the most strongly influencing factor is the gap (SW) between the folded feed

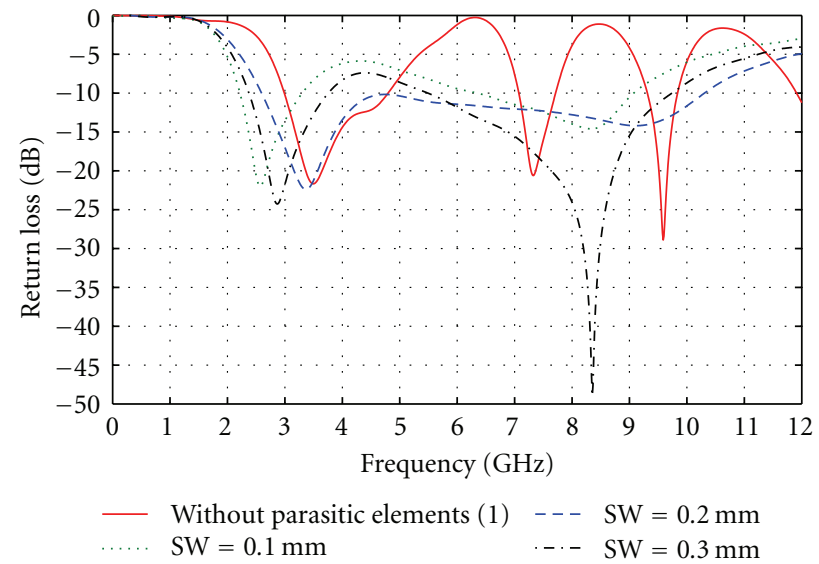

FIGURE 2: Simulated return losses due to width of gap (SW) between a folded feed line and a parasitic element (1).

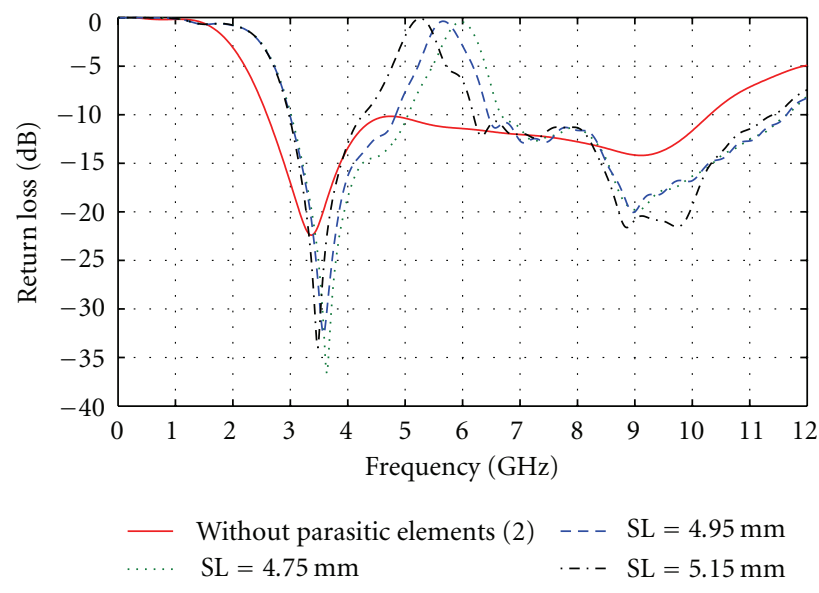

FIGURE 3: Simulated return losses due to height (SL) of a parasitic element (2).

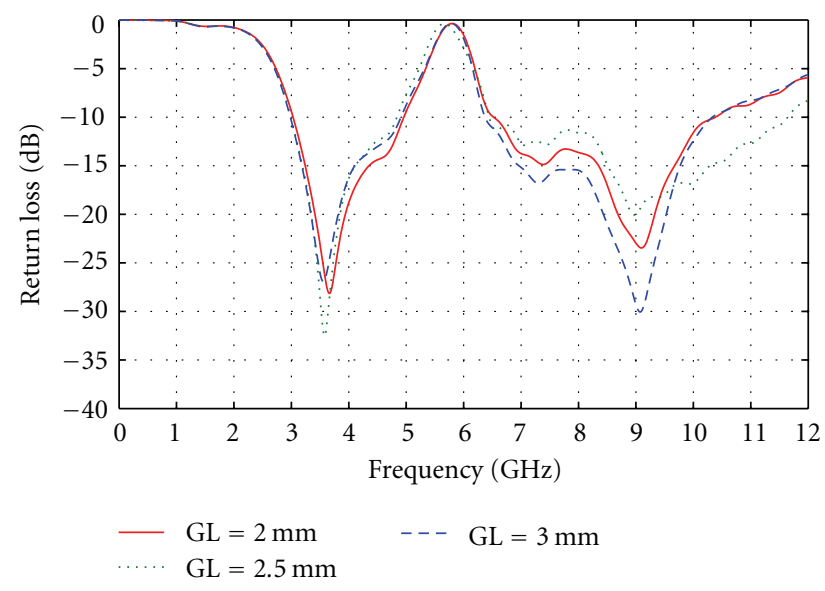

Figure 4: Simulated return losses due to parameter GL. 


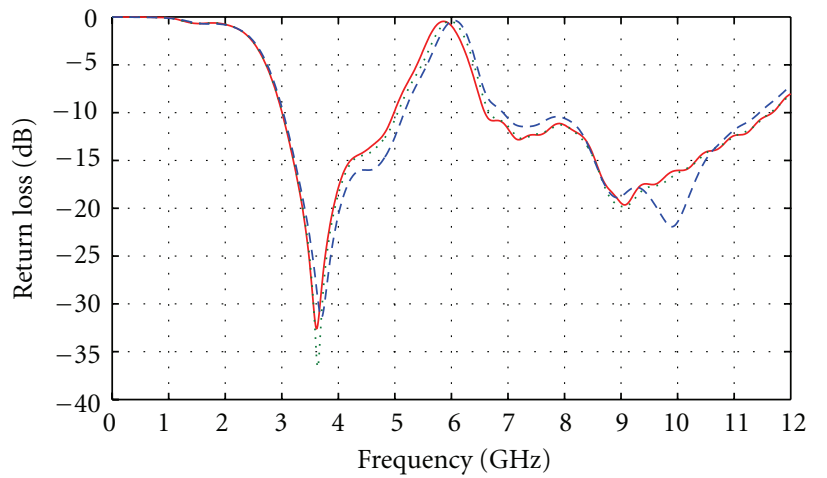

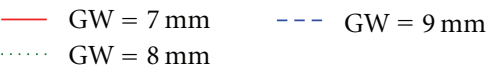

FIGURE 5: Simulated return losses due to parameter GW.
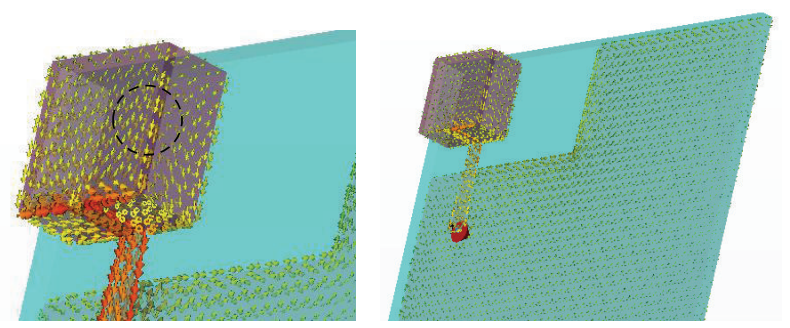

(a)
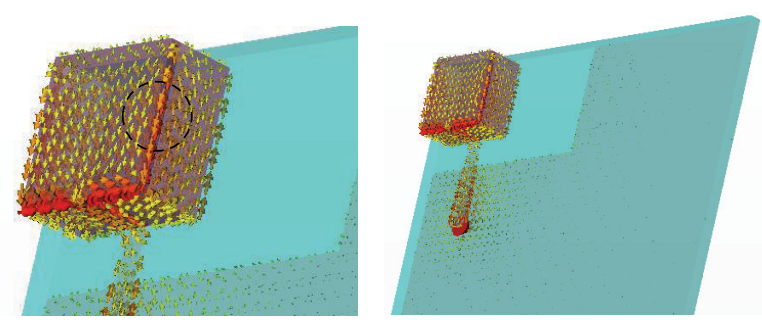

(b)

FIgURE 6: Current distribution of gaps between radiator and side parasitic elements for band-stop. (a) $3.15 \mathrm{GHz}$, (b) $5.8 \mathrm{GHz}$.

line and each parasitic element (1). The results are shown in Figure 2 and compared with an antenna without parasitic elements (1). It can be seen that impedance matching can be enhanced by adding parasitic elements into the radiator and adjusting their widths. The width of $0.2 \mathrm{~mm}$ is determined after considering characteristic of return losses.

The variations of design parameters due to SL are shown in Figure 3. It can be observed that the desired band-stop characteristic can be obtained from the gap formed by adding a parasitic element (2), and the center frequency for the band-stop function can be varied by adjusting the height (SL) of a parasitic element (2). The length of SL is determined to be $4.95 \mathrm{~mm}$ which is the lambda/4 at about $5.725-5.825 \mathrm{GHz}$ for considering dielectric constant of 4.5 in the dielectric block. The return losses of the proposed antenna due to parameter GL and GW are also shown in Figures 4 and 5. It can be observed that their

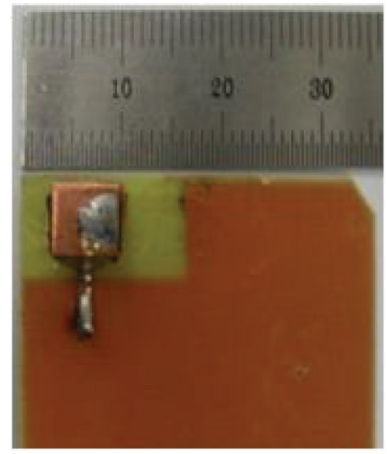

(a)

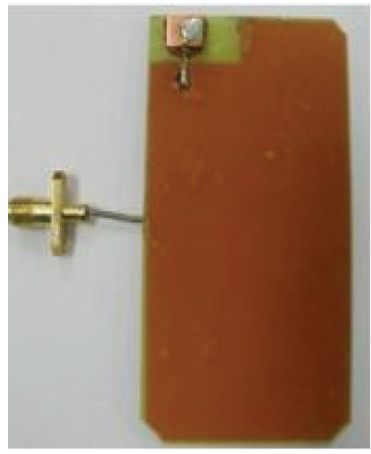

(b)

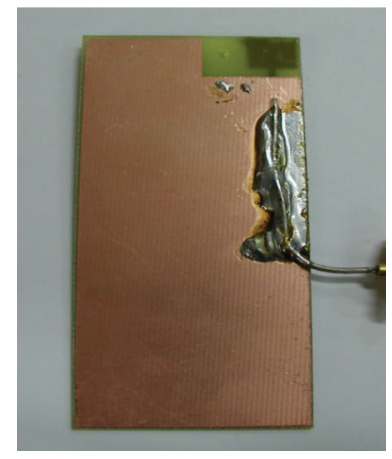

(c)

Figure 7: Photo of the proposed antenna.

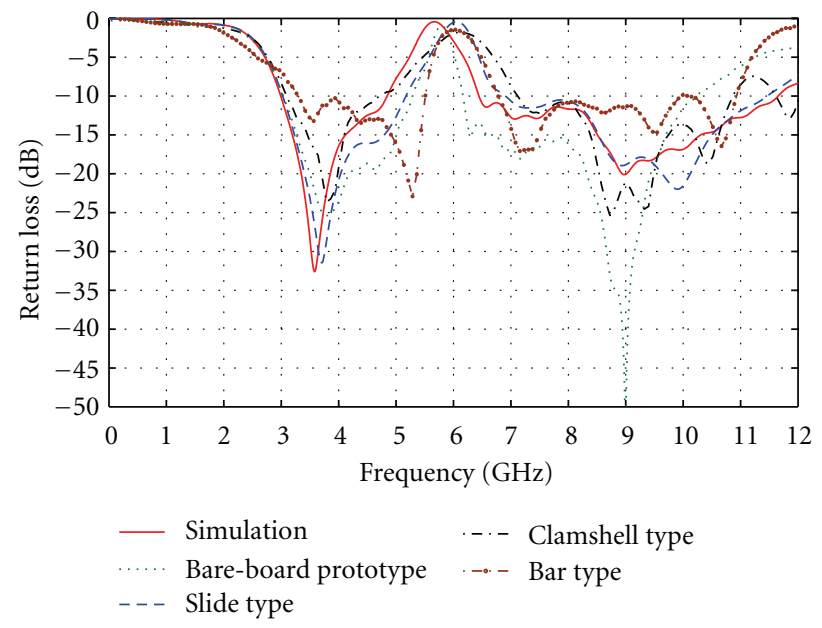

FIGURE 8: Measured return loss of the proposed antenna for the various mobile terminals.

patterns are not largely influenced by those parameters. The current distribution around lambda/4 short stubs for the band-stop function at $3.15 \mathrm{GHz}$, compared with $5.8 \mathrm{GHz}$, is shown in Figure 6. Currents around the radiator and gaps have the same direction, and currents are distributed to the entire ground plane at $3.15 \mathrm{GHz}$, while opposite currents are strongly generated at gaps, and most of the currents are not delivered to the ground plane at $5.8 \mathrm{GHz}$. 


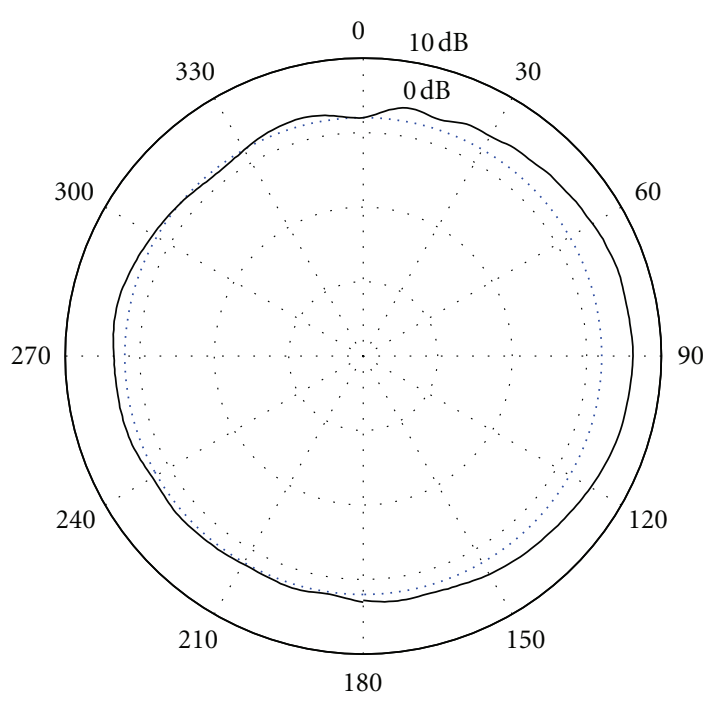

Simulated radiation pattern — Measured radiation pattern

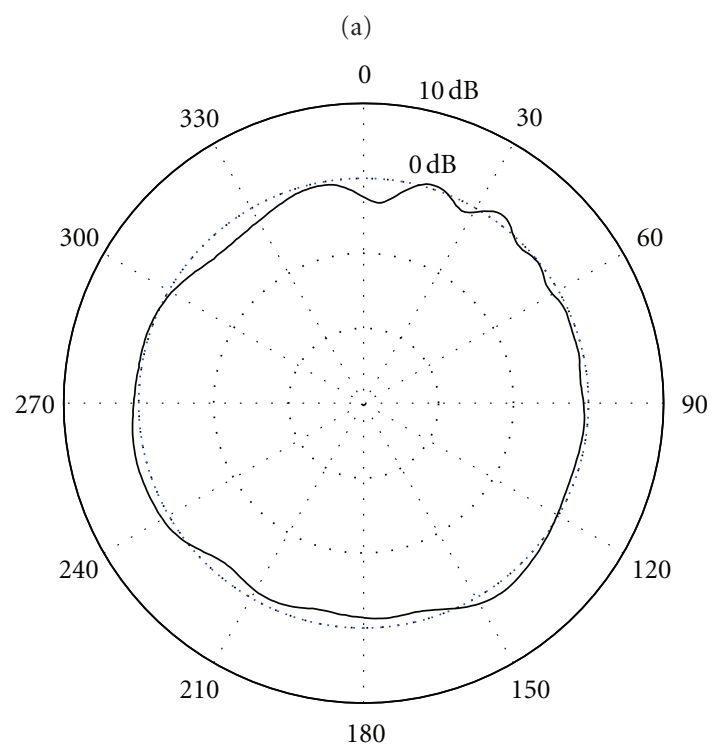

Simulated radiation pattern

— Measured radiation pattern

(b)

FIguRE 9: Simulated and measured XZ-plane patterns of the proposed antenna, $10 \mathrm{~dB}$ per division. (a) $3.15 \mathrm{GHz}$, (b) $7.2 \mathrm{GHz}$.

\section{Experimental Results}

Photos of the proposed antenna on the PCB are provided in Figure 7, showing that the proposed antenna has a very compact size. The proposed antenna is located in the top left corner of the PCB. It is directly fed by coaxial cable on the reverse side of the $\mathrm{PCB}$, and the feeding point is connected through a via. The tapered feed line of the antenna is directly printed on the PCB and dielectric block. The main radiator
TABLE 1: Absolute gain of the proposed antenna for the various mobile terminals.

\begin{tabular}{lccc}
\hline \multirow{2}{*}{ Model } & \multicolumn{3}{c}{ Maximum gain [dBi] } \\
& $3.15 \mathrm{GHz}$ & $5.8 \mathrm{GHz}$ & $7.2 \mathrm{GHz}$ \\
\hline Bare-board prototype & 5.75 & -14.34 & 1.07 \\
Slide type & 1.71 & -13.42 & 0.21 \\
Clamshell type & 2.79 & -16.24 & 2.65 \\
Bar type & 1.42 & -18.15 & 1.31 \\
\hline
\end{tabular}

and parasitic the elements (1) and (2) are also attached to the dielectric block after each etched pattern is fabricated.

The proposed antenna was housed in three kinds of handset terminals of bar, slide, and clamshell type in order to conduct measurements, and those return losses are shown in Figure 8 compared with the return loss of a bare-board prototype type that does not consider handset terminals. That shows that the impedance bandwidths with VSWR less than 2 are $3.15-4.75 \mathrm{GHz}$ and $7.2-10.2 \mathrm{GHz}$. These cover all UWB bands and reject the band at $5.725-5.825 \mathrm{GHz}$. The measured radiation patterns of the proposed antenna are compared with simulated results at 3.15 and $7.2 \mathrm{GHz}$, as shown in Figure 9. These radiation patterns are omnidirectional, and it is observed that the measurement and simulation results are in good agreement.

The radiation patterns of the proposed antenna housed variously with handset terminals of bar, slide, and clamshell types were also measured at $3.15,5.8$, and $7.2 \mathrm{GHz}$, as shown in Figure 10. The antenna housed with handset terminals is influenced by the terminals, distorting those patterns. Table 1 shows the measured maximum gain of the proposed antenna, which is the absolute gain considering the reflections from the antenna [19]. It varies from $1.07 \mathrm{dBi}$ to $5.75 \mathrm{dBi}$ on the XZ-plane except in the stop band of the proposed antenna which has maximum gain from -0.21 to 2.79 when the antenna is housed with a mobile terminal.

\section{Conclusion}

We proposed a UWB antenna loaded by parasitic elements for mobile handsets to operate over all UWB bands with a band-stop function. This design can have wide impedance matching due to the parasitic elements (1) that are incorporated into both sides of a folded feed line. Moreover, the proposed antenna can have band-stop characteristic that are created by adjusting the lengths of a pair of parasitic elements (2). This proposed method can cover all UWB bands of 3.154.75 GHz and 7.2-10.2 GHz for VSWR less than 2, while $5.725-5.825 \mathrm{GHz}$ is notched. The proposed antenna has very compact size and it is very easy to implement by bending a simple metal plate into a compact structure. Ultimately, this design has strong potential for the next generation of convergence between UWB system and mobile handsets. 


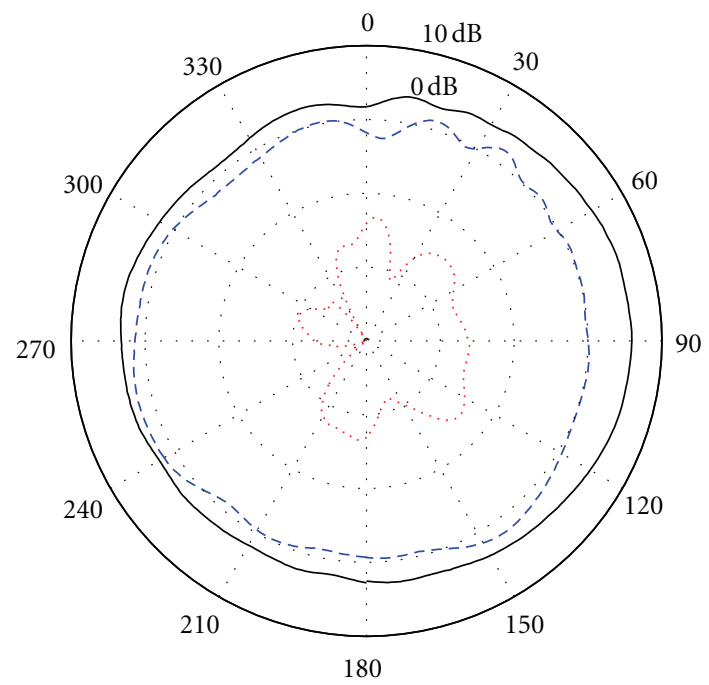

(a)

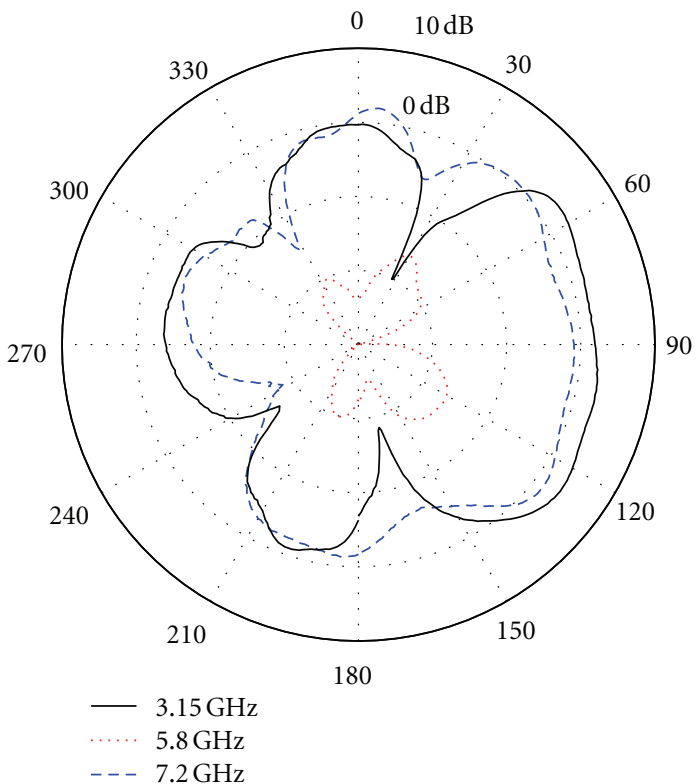

(c)

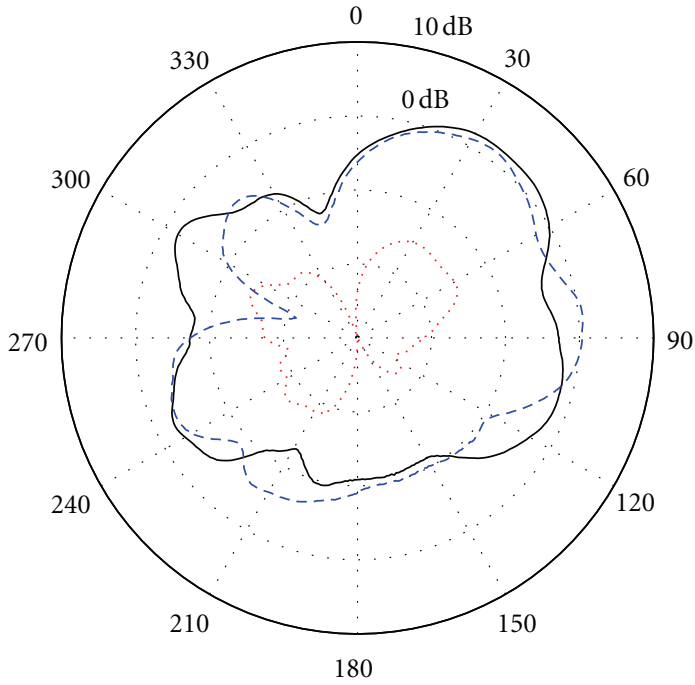

(b)

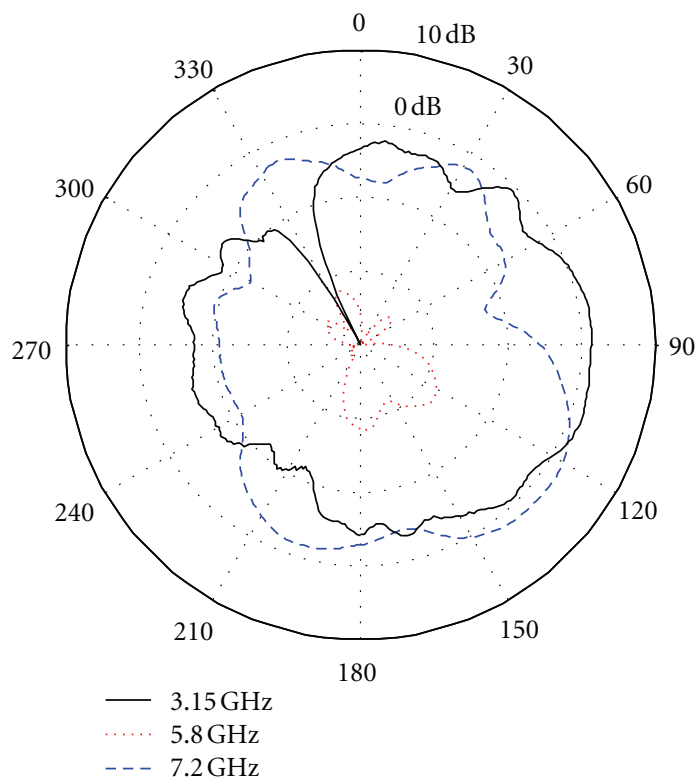

(d)

Figure 10: Measured XZ-plane pattern of the proposed antenna for the various mobile terminals, $10 \mathrm{~dB}$ per division. (a) Bare-board prototype, (b) slide type, (c) clamshell type, (d) bar type.

\section{Acknowledgment}

This research was supported by LG Electronics, Seoul, Korea.

\section{References}

[1] J. Timmermann, M. Porebska, C. Sturm, and W. Wiesbeck, "Investigating the influence of the antennas on UWB system impulse response in indoor environments," in Proceedings of the 4th European Radar Conference (EURAD '07), pp. 283-286, October 2007.

[2] I. J. Yoon, H. Kim, Y. J. Yoon, Y. H. Kim, and H. K. Yoon, "Ultra-wideband tapered slot antenna with band cutoff characteristic," Electronics Letters, vol. 41, no. 11, pp. 629-630, 2005.
[3] H. K. Yoon, Y. J. Yoon, H. Kim, and C. H. Lee, "Flexible ultrawideband polarization diversity antenna with band-notch function," IET Microwaves, Antennas \& Propagation, vol. 5, no. 12, pp. 1463-1470, 2011.

[4] Y. Lim, H. K. Yoon, S. Kwak, B. S. Lee, Y. J. Yoon, and Y. H. Kim, "The design of three-dimensional folded fat-monopole antenna for UWB radio system," International Journal of Microwave and Optical Technology, vol. 1, no. 2, pp. 813-819, 2006.

[5] H. K. Yoon, W. S. Kang, Y. J. Yoon, and C. H. Lee, "A flexible UWB antenna attachable to various kinds of materials," in Proceedings of the IEEE International Conference on UltraWideband (ICUWB '07), pp. 204-209, September 2007.

[6] R. Fallahi, A. A. Kalteh, and M. G. Roozbahani, "A novel UWB elliptical slot antenna with band-notched characteristics," 
Progress in Electromagnetics Research, vol. 82, pp. 127-136, 2008.

[7] Z. A. Zheng and Q. X. Chu, "CPW-fed ultra-wideband antenna with compact size," Electronics Letters, vol. 45, no. 12, pp. 593-594, 2009.

[8] G. Cappelletti, D. Caratelli, R. Cicchetti, and M. Simeoni, "A low-profile printed drop-shaped dipole antenna for wideband wireless applications," IEEE Transactions on Antennas and Propagation, vol. 59, pp. 3526-3535, 2011.

[9] A. Godard, L. Desrumaux, V. Bertrand et al., "A transient UWB antenna array used with complex impedance surfaces," International Journal of Antennas and Propagation, vol. 2010, Article ID 243145, 8 pages, 2010.

[10] C.-H. Liao and D.-C. Chang, "A large aperture UWB antenna array for real beam radar imaging," International Journal of Antennas and Propagation, vol. 2012, Article ID 639603, 7 pages, 2012.

[11] K. S. Ryu and A. A. Kishk, "UWB antenna with single or dual band-notches for lower WLAN band and upper WLAN band," IEEE Transactions on Antennas and Propagation, vol. 57, no. 12, pp. 3942-3950, 2009.

[12] W. Li, X. Shi, T. Zhang, and Y. Song, "Novel UWB planar monopole antenna with dual band-notched characteristics," Microwave and Optical Technology Letters, vol. 52, no. 1, pp. 48-51, 2010.

[13] J. Xu, D. Y. Shen, G. T. Wang, X. H. Zhang, X. P. Zhang, and $\mathrm{K}$. Wu, "A small UWB antenna with dual band-notched characteristics," International Journal of Antennas and Propagation, vol. 2012, Article ID 656858, 7 pages, 2012.

[14] S. W. Su, J. H. Chou, and K. L. Wong, "Internal ultrawideband monopole antenna for wireless USB dongle applications," IEEE Transactions on Antennas and Propagation, vol. 55, no. 4, pp. 1180-1183, 2007.

[15] D. D. Krishna, M. Gopikrishna, C. K. Aanandan, P. Mohanan, and K. Vasudevan, "Ultra-wideband slot antenna for wireless USB dongle applications,” Electronics Letters, vol. 44, no. 18, pp. 1057-1058, 2008.

[16] Y. C. Chang, C. Y. Wu, and C. C. Chiu, "A ultra-wideband monopole antenna for wireless applications," in Proceedings of the International Kharkov Symposium on Physics and Engineering of Microwaves, Millimeter and Submillimeter Waves (MSMW"10), June 2010.

[17] H.-C. Tang and K.-H. Lin, "Miniaturized asymmetrical triangle UWB antenna for WUSB dongle applications," in Proceedings of the IEEE International Symposium on Antennas and Propagation, pp. 1467-1469, 2011.

[18] A. Abdin, "Characteristics of a multi bandwith gear microstrip antenna using a taper for feeding," in Proceedings of the Progress in Electromagnetic Research Symposium (PIERS '09), Beijing, China, March 2009.

[19] C. A. Balanis, Modern Antenna Handbook, John Wiley \& Sons, Hoboken, NJ, USA, 2008. 

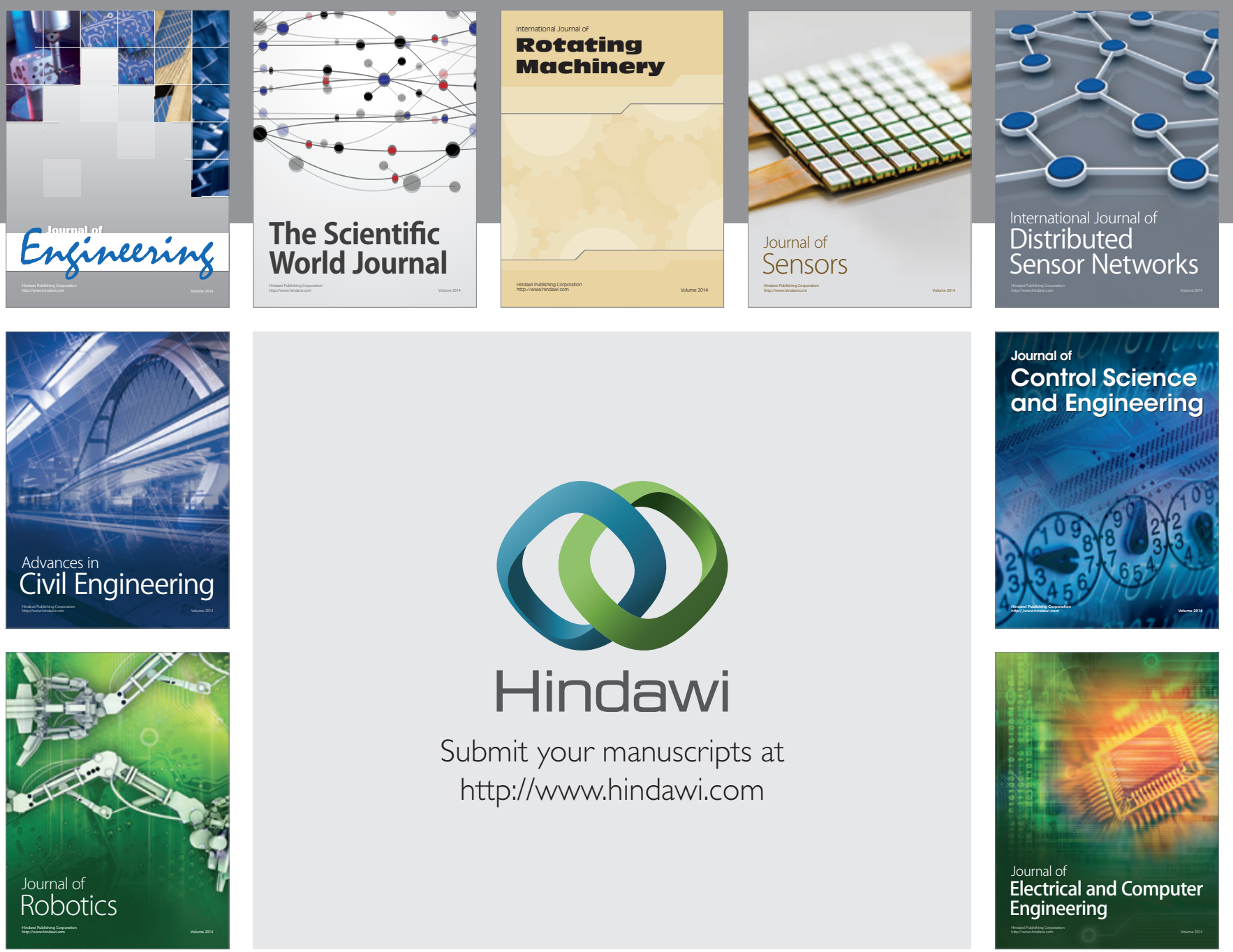

Submit your manuscripts at

http://www.hindawi.com
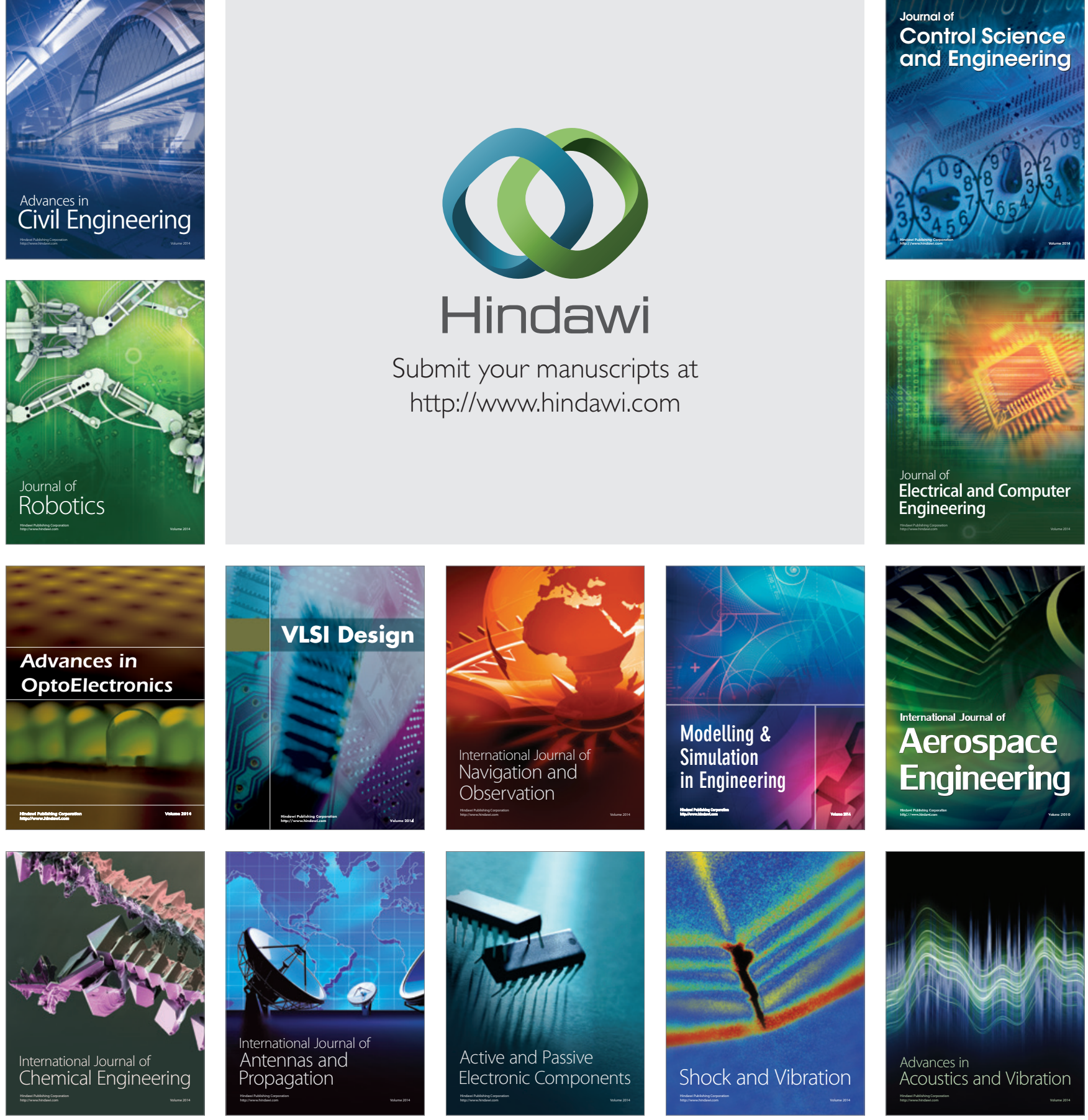